\title{
Integral Research of the Modern Art Concept's Influence on the Indoor Space Form
}

\author{
Fulan Chen \\ Guangzhou Vocational College of Science and Technology \\ Guangzhou, China
}

\begin{abstract}
In this thesis, the mentioned "Art Conceptualization" is mainly indicating a kind of generalized art behavior, and the art work has aesthetical features convective factors, includes the aesthetics spirit characteristics of the traditional easel painting fields, meanwhile, it also should include the wider art forms language and art thinking concept of the modern art fields. It is kind of the factor in the form of the tangible art works, and meanwhile it is also kind of the concept existence in spirituality.
\end{abstract}

\section{Keywords - interior design; environmental art}

\section{INTRODUCTION}

Our mankind has entered the 21st century, and in current times, development is based on the design. The interior design is one the important activities for improving human beings'material and cultural life and living environment, the core of the design is to keep creating continually, to create a better and more suitable activity space and aesthetic space for people. Under the effect of the conceptual art and architectural art, to improve the interior design up to a higher level with a very suitable condition and to create more pioneering and original interior design artworks are the responsibilities for present interior designers, adopting the value orientation of diversity and variety and also the aesthetic orientation of our excellent traditional culture.

\section{The Cultural CONNOTAtion OF THE Chinese TRADITIONAL INTERIOR CULTURE}

The Chinese traditional interior design often pursue that itself can be harmonious with the natures and then make some differences based on this harmony; the traditional interior design lay emphasis on the unification, sequence and symmetry; stressing on connotation and plainness, illusion and reality. Abstracting is highly appreciated by the interior design. The modeling is objective to spirits expression, no matter with the overstatement or omission. All the aspects of the interior design are based on the artistic conception's creating. From the decoration form to the interiors and exteriors space organizing, from the decoration patterning to calligraphy and paintings display, from the decoration materials to decoration structures, the interior design use a lot of implication and symbolization, overflowing with the beauty of images.

The Chinese traditional interior art design has already reached to a very high level. Looking back to its origin, actually the Chinese ancient wooden architecture structure system is the originator for the modern structures. Such an advanced system endows enough freedom for the interior space. And the combination and transmutation among different single architectures, to evaluating the abundant space annotation, creating the space formats as movement and stillness uniform, the internal and external communication, connotation and variation. We should flexibly unify the interior and exterior space of the architecture by using hollow corridors, hollow doors, hollow windows, perforated windows and perforated screen and fans. Internal and external eaves decorations now become the special design words for the interior design. The ceiling and caisson, partition board, cover, shelves, and checks become the decoration elements for dividing the interior space. Moreover, the Chinese traditional interior decoration and display art also reach to a very high level as it profound cultural connotation. Whether the emperor royal palace, officialdom house or civilian yard, they all lay their furniture and house by symmetrical axis. The tablets, couplets, paintings, chairs, squared table, and some meaningful bottles and mirrors, form into a perfect decoration picture.

In this design, we can feel a concept of visible, habitable, playable features. And this space is very suitable for human beings freely development. In all, the Chinese traditional interior art design is very important cultural resource of our modern people.

\section{THE MOdERN ART'S INFLUENCE ON THE MODERN DESIGN}

\section{A. The Modern Design Revolution are Motivated by the Explore of Modern Arts}

In the late 19th century, the modern design revolution is pushed by the radical exploration of painting circle in modern arts. The specific understanding of composition for Art Circle, started from Impressionist Cezanne in the late 19th century. Cezanne's painting composition and its methodology, and the composition of the solid modeling is the same. Cezanne on awareness and impact the Trang, Henri Matisse, Uruk, and led them to establish the "beast". And then a "Futurist" art is established, and "Futurism" is developed into the revolutionary "Dada". Its performance goes throughout the geometric, abstract form of consciousness. Influenced by Cubism, Futurism, constructivism and other effects, progressive designers challenge tradition, developed in line with modern 
design style of the times. Cubism was among the first-time space concept into a visual image of the artistic trends. It uses the principle of relativity and the principle of simultaneity, simultaneously observe objects at different time out shown in picture is more pure geometric form. Painter Piet Mondrian was Netherlands source of philosophy of the style and Visual development. He was under the influence of cubism, avantgarde art, and rejected the design work of all elements, to reduce the visual vocabulary to use red, yellow, blue and black and white, shape and sculpt only square and rectangular, with solemn asymmetrical composition, reach an absolute harmonious state of tension and balance.

Affected by this, Designer Rietveld's "Red and Blue Chair" and "Schroeder" House Design, expand the Modrian's two-dimensional composition into the three dimensional space, become one of the most famous representative works of the Destijl, and a very important milestone in the exploration for modern design forms. The Identity of industrial production is strengthening the requirements for order and simplicity makes design embodies order, designers began to abandon the trappings of traditional practices. Modern Germany designer under the influence of Le Corbusier and others simple, treating the geometric as a sacrosanct principle of design, decorated with exclusive, this is known for its focus on basic forms, becoming the pioneer of rationalistic design.

In Conclusions, these modern arts features are compatible with requirements of the big machinery batch production's standardization and mechanization skill, becoming the inevitable choice for big machine production. Based on these two sides combination, the modernism design is emerged.

\section{B. The New Art Form and Design Form Emerged under the Influence of Modern Art and Modern Design}

Along with the alternation and transformation of super modernism, expressionism, constructivism, the design form are changing as the modern art, including the development of forms and language and also the colorful hyperspace conception with spiritual connotation. In the 1960 of the 20th century, installation art with an open attitude, fully absorbing the painting, design, commercial and domestic waste and all other modeling tools and language factors, has created a new field of art. This concept soon impact on the visual design. Meanwhile, the painting also affected by revelations of design and business culture, such as Richard Hamilton photos, posters, posters printed materials is "what makes today's homes so different so attractive", and becoming the forerunners of pop art. To depending on illusion, and has order changes of image repeat, and formed Visual of dynamic and illusion of op art, performance of is another a rely on Visual residual like and the depending on illusion performance of media form, later development into dynamic art, plus sound, and light, and shadow formed a space, and stereo, and plane of integrated art, depends on people of retinal image illusion raised psychological phenomenon by show of a decorative taste of media design. This style of design in posters, television images, often adopted for the design of packaging design. The post modernism originated from the $70 \mathrm{~s}$, which is a rebellion of international style, in pursuit of a vibrant, diverse culture. By using the past Victorian, Art nouveau and Art Deco styles, many designers are inspired of the nostalgia, modernization are used into the old art form, so the products are with strong artistic creation significance, to expand the design concepts and vocabulary.

\section{To Endow a Brand-new Concept for Interior Design}

Interior Design is one part of the mankind surviving activities; meanwhile it is kind of the manner for mankind creating activities. The interior design is based on the environment of the architecture practical nature and relative standards, taking the modern design esthetic as principle, using the modern material technique methods and utility function and aesthetic function, to create this design activity to meet people's material and spiritual living requirements. Meanwhile, it is also the obligation for interior design to supply people a very good environment for materials, living and surviving, to meet the mankind's requirements for utility function. It is a essential step to break the present interior design's inherent theory mode. For instance, in the specific interior design application, many interior design art works are very similar in style, which are pay attention to the perfection and luxury design, neglecting more important art elements' construction issues. Duchamp makes some modification on the present ready-made work, then put it into the space under certain environments, then this work are endowed a brand-new concept and becoming a genius artwork. So in the new concept context, the relationship between people and object are obtained another new explanation and reading. The classical "Mona Lisa" is heavily painted by him with two moustaches, to break the easel painting insurmountable mode as bible, opening up a brand new idea space for art development. This is the conceptual embodiment in pure art fields. Meanwhile, stimulating the traditional modern artist to get rid of the tradition's constraint, to attempt the new methods and to analysis the history of art, and then to grasp the trends of art development.

\section{THE INTERIOR COMPLETE FORM}

Modern Western-type decorations from rich luxury, the pursuit of luxury, tend to be on the practical function and effectiveness. If the style of the Bauhaus school, from the traditional wall mounted indoor, full range of precious furniture, chandeliers and layout art treasures out of decorating, and pursuit of sufficient living space, ample sunlight and good ventilation, and feature comfortable furniture and equipment, supplies, eclectic.

With characteristics of masters like to lay out the interior decoration and furnishings, such as the simple and elegant sofa, coffee table, refined and beautiful combinations of cabinets, kitchens and a full range of equipment and all sorts of beautiful lamps, thus becoming the modern interior design. France scholars Levy - Bruhl has had said such words: after more and more study on developed nations, then found some surprising similarities of some nationalities, sometimes even the smallest nuances of reached on exactly the same point. Found in the different national systems, with some magic or religious rituals, with some of the beliefs and customs of life and death, with a number of myths and so on, comparative methods can be said to have emerged. In the field of Interior design is no exception. 
Here, we will compare the interior design studies as an independent discipline. Now we are in a worldwide communication, China is like a big construction site, more and more foreign architects to design here, so now the Chinese interior design seems it will be replaced by foreign culture in future.

\section{THE CONCEPT OF MODERN ART - INTERIOR DESIGN}

Some young people in china, they have kind of inclination that the old objects no longer has value of existence when they mention and praise the western modern design and cultural school of art. It seems they think the old objects are doomed to extinction when the new objects emerged. However, the history development is not in this logic. The environmental art design as the man-created materials products and times culture symbol, the different artworks did not vanish in different eras, only "solidification" at some moments of the history, staring the times' developing. Now the birth of the modernism did not bury classicalism's light, instead, it became the base of modernism. The emergence of postmodernism, not as Jenks asserted - "announced the demise of modernism"; on the contrary, driven by great designers such as Ieoh Ming Pei and Gary, it firmly steps towards the 21 st century. In fact, modernist designs as a symbol of industrial civilization, in the history of environmental art design leaves a lot of monuments. In practice some of the principles of creation even today still have some kind of positive significance and progress. Current interior design in General is still in a "design" itself as the Center, focused on the design of "law", as well as for the design of "practical" on stage, of course, associated with the stronger commercial penetration with huge. But to be fair, how many artistic contents are there in the interior design? Or let us look at the situation in China, the local state of the environment for the development of the concept art! Conceptual art in the context of contemporary culture is actually originated from a cultural paradox, it is the inevitable product of the global postmodern, postcolonial cultural vocabulary, but also it is the reconstruction of Chinese contemporary art text based on the western conceptual art language.

The modern art design and modern art also are affected by the thinking wave, market system, economy discipline, the personal design model and group design model of the modern design are updating with the era development. In front of the idea art, modern designer also face a miserable choice, which is the value judgment between the powerful economy market driving and the pursuit of the art creation. How to find the critical point of these two poles is the great and unavoidable problem for contemporary designers. It is very easy that we could find the idea transformation and idea art development of the interior design should have the very similar spiritual features, In the idea arts, the flexibility of the paintings, the conceptualization of culture, far beyond the utility and utilitarian of the interior design, then embodied with operability and strong aesthetic infectivity, reaching the deepest cultural context of mankind art essence. So just because the interior design itself frontier science restrictions, so the art scope it can touched is different from the idea paintings and other art forms. Interior design in commodity economy, science and technology, computers, new materials derived from the under the influence of new faces, as well as industrial products after the industrial revolution, mass production, machine-made, has a strongly stylized and pretentious but lack the most infection-individual characteristics and cultural connotation. So, to change this situation, the interior design on a healthy, orderly, and idealized way of development, interior design activities focus should be flocking to the concept of conversion, for more art of factors of influence, rather than a simple search of forms and materials. Indoor design should heavy in style form has more level of breakthrough, advocates design territories has comments of academic atmosphere, advocate adapted each times or stage different of design mainstream, followed art development of itself law and law, reached must period within design mainstream concept convergence, and performance form diversified of ideal State, re-building the new interior design thinking and concept, while combing and understanding the latest modernism interior design history, to think again and research the relationship between the internationalization and localization, focus on the management and construction of the interior design activities by aesthetics and tastes, environment and atmosphere, rebellious and reconstruction, psychological feelings and culture.

\section{CONCLUSION}

The purpose of the interior design is to create a better living space for human beings. In the design, utility and aesthetics are same important, beautification is part of the design but not the whole. The designers should objectively to understand and make the processing scheme, trying to experience the user's ideas to make use of the space, avoiding any self-approbation and unrealistic. As for the designers, except for the requirements of customers and also need to consider the need of the end user, in order to balance the importance of utility and creativity.

\section{REFERENCES}

[1] Wenjian. Indoor soft adornment design tutorial [M]. Tsinghua University Press, 2011.

[2] Dong Wanli.Environmental Art Design Principles [M]. Chongqing University Press, 2003.

[3] Dave-Bright.Decoration New Thoughts-Pleasure in visual art and ideology [M]. PPMG, 2006.

[4] Yin Dingban. Introduction to design [M].Hunan Science and Technology Press, 2001.

[5] Zhang Guolong. Contemporary·Art-Materials·Space [M].Jilin publishing group co., tld, 2006.

[6] Liu Feng. Contemporary art and interior design $[\mathrm{J}]$. Dacheng aesthetic education, 2013 (3)

[7] Cui Donghui. The conspectus of interior design [M].Beijing: Beijing University Press, 2007 